\title{
Probióticos: una alternativa para la industria de alimentos
}

\author{
Rafael Villanueva Flores \\ Universidad de Lima. Lima, Perú \\ Correo electrónico: RVillan@correo.ulima.edu.pe \\ Recibido: 20 de enero de 2015 / Aprobado: 20 de julio de 2015
}

\begin{abstract}
Resumen: Existe un mercado creciente para alimentos que contienen bacterias probióticas y una amplia variedad de cepas probióticas se están añadiendo principalmente a productos lácteos. La capacidad de las cepas probióticas para sobrevivir a las condiciones encontradas en los procesos de fabricación industriales (temperatura, $\mathrm{pH}$, oxígeno disuelto, concentración de azúcar, etc.) es el principal obstáculo que los fabricantes de alimentos deben superar. La estabilidad térmica del Bacillus subtilis representa una buena alternativa para la producción de panes, galletas y otros productos horneados.
\end{abstract}

Palabras clave: probiótico / prebiótico / pan / productos horneados

\section{Probiotics: An Alternative for the Food Industry}

ABstRACT: There is a growing market for foods that contain probiotic bacteria, and a wide variety of probiotic strains are being added mainly to dairy products. The ability of probiotic strains to survive conditions encountered in industrial manufacturing processes (temperature, $\mathrm{pH}$, dissolved oxygen, sugar concentration, etc.) is the main obstacle food manufacturers must overcome. Bacillus subtilis represents a good alternative for the production of bread, crackers and other baked products.

Key words: probiotic / prebiotic / bread / baked products 


\section{INTRODUCCIÓN}

El origen del consumo de alimentos probióticos, debido a los beneficios que presentan para la salud, data de principios del siglo XX. En 1908, el científico ruso y premio Nobel de Fisiología o Medicina 1908 Eliot Metchnikoff postuló que las bacterias ácido-lácticas ofrecían beneficios para la salud que llevaban a la longevidad al observar que los campesinos en Bulgaria gozaban de una vida longeva y saludable, gracias al consumo de yogur y otros productos lácteos fermentados. Sugirió que la "autointoxicación intestinal" y el envejecimiento resultante podrían suprimirse modificando la flora intestinal y utilizando microbios útiles para sustituir a los microbios proteolíticos como el Clostridium (productores de sustancias tóxicas que surgen de la digestión de proteínas, entre las que se encuentran fenoles, índoles y amoniaco) por microbios útiles. Desarrolló entonces una dieta con leche fermentada por bacteria, a la que denominó "bacilo búlgaro".

El término probiótico fue introducido por primera vez por Lilly y Stillwell en 1965, definiéndolo como aquel factor de origen microbiológico que estimula el crecimiento de otros organismos. En 1979, Parker los definió como organismos y sustancias que contribuyen al balance intestinal microbiano; y en 1989, Fuller enfatizó el requisito de viabilidad e introdujo la idea de que tiene un efecto beneficioso para el huésped.

Los probióticos pueden ser considerados como ingredientes funcionales que se utilizan para adicionar una propiedad definida, que le otorga un valor agregado al alimento que lo contiene (Cáceres y Gotteland, 2010). Los productos alimenticios entre cuyos componentes se encuentran los probióticos ingresan, por lo tanto, en la categoría de alimentos funcionales, pues proporcionan beneficios para la salud del consumidor más allá de los nutricionales propios del alimento (Hasler, Bloch, Thomson, Enrione y Maning, 2004).

El crecimiento rápido del mercado de probióticos se produce en la industria de los alimentos, dado que existe una tendencia a consumir alimentos enriquecidos con probióticos en vez de consumir comprimidos, cápsulas o suplementos con probióticos (Bruhn et al., 2002).

\section{PROBIÓTICOS Y PREBIÓTICOS}

Los probióticos son definidos por la Organización de las Naciones Unidas para la Agricultura y la Alimentación (FAO) y la Organización 
Mundial de la Salud (OMS [WHO, por sus siglas en inglés]) como organismos vivos, que cuando son administrados a un huésped en cantidades adecuadas le deparan beneficios para la salud. También incluye una definición de género, especie y cepa, tanto como estudios de seguridad y eficacia en humanos (FAO/WHO, 2001). Los efectos beneficiosos en la salud humana y la nutrición de los alimentos con microorganismos vivos agregados (probióticos) han sido cada vez más reconocidos por los profesionales de la salud.

Trabajos científicos recientes acerca de las propiedades y funcionalidad de los microorganismos vivos en los alimentos señalan que los probióticos desempeñan una acción importante en las funciones inmunológica, digestiva y respiratoria y podrían tener un efecto significativo en el alivio de enfermedades infecciosas de los niños y de otros grupos de alto riesgo (FAO, 2006).

Las fibras prebióticas son alimentos no digeribles fermentadas en el colon por bacterias específicas promotoras de la salud (O'Neill, 2007). Nutren a grupos seleccionados de microorganismos que habitan en el intestino, favorecen el crecimiento de bacterias beneficiosas sobre las nocivas y dan lugar a cambios específicos en la composición y actividad de la flora gastrointestinal, proporcionando así beneficios a la salud del huésped $\left(\mathrm{WGO}^{1}, 2011\right)$. Estos compuestos se caracterizan por ser moléculas de gran tamaño que no pueden ser digeridas por las enzimas digestivas del tracto gastrointestinal alto, alcanzando el intestino grueso, donde son degradadas por la microflora bacteriana (Olagnero et al., 2007). Los prebióticos más investigados son la inulina y los oligosacáridos (O'Neill, 2007). Los prebióticos ayudan a prevenir trastornos digestivos, y hay indicios de que también juegan un papel importante en el retraso del proceso de envejecimiento y el aumento de la longevidad (O'Neill, 2011). Los prebióticos no deben ser confundidos con los probióticos, que son bacterias saludables "vivas" encontradas en alimentos que consumimos (O’Neill, 2011). Los microorganismos probióticos deben permanecer viables y activos en el alimento durante el pasaje gastrointestinal para garantizar así su potencial benéfico en el huésped (Saarela, Mogense, Fondén, Matto y Mattila-Sandholm, 2000).

Una cepa probiótica se identifica por su género, especie y una designación alfanumérica. La comercialización y los nombres comerciales no

1 Organización Mundial de Gastroenterología (WGO, por sus siglas en inglés). 
están regulados y las compañías pueden ponerle el nombre que deseen a sus productos probióticos. Debido a que las propiedades probióticas son cepa-específicas, es importante tener bien rotulados estos productos con el nombre de la(s) cepa(s) presente(s), de tal manera que tanto los profesionales de la salud como los consumidores puedan diferenciar entre los distintos productos disponibles en función de la cepa que contienen (Cáceres y Gotteland, 2010).

Los probióticos, bacterias de los géneros Bifidobacterium y Lactobacillus, y la levadura, Saccharomyces, así como los prebióticos que pertenecen al grupo de fibra dietaria (inulina con bajo grado de polimerización, oligosacáridos de derivados de fructosa y el almidón resistente) son factores naturales útiles en la profilaxis y en la terapia de varias enfermedades comunes, incluidos algunos tipos de cáncer. Están disponibles comercialmente y se pueden adquirir para producir los denominados alimentos funcionales. Los probióticos y prebióticos pueden ser utilizados, sea por separado o en conjunto, como simbióticos o eubióticos (Przemyslaw y Piotr, 2003).

\section{MECANISMOS DE ACCIÓN}

Los prebióticos afectan las bacterias intestinales, aumentando el número de bacterias anaeróbicas beneficiosas y disminuyendo la población de microorganismos potencialmente dañinos.

Los probióticos afectan el ecosistema intestinal, estimulando tanto los mecanismos inmunitarios de la mucosa como los mecanismos no inmunitarios, a través del antagonismo y competencia con patógenos potenciales (WGO, 2011).

\section{ROL DE LA FLORA INTESTINAL}

Los probióticos son usados con el fin de que ayuden a la flora intestinal, que aparece naturalmente en el organismo humano y es única para cada persona, a manera de huella digital. En general, la mayor evidencia clínica para los probióticos está vinculada a su uso en la mejora de la salud intestinal y la estimulación de la función inmunitaria (WGO, 2011). Los probióticos colonizan el tracto digestivo y se adhieren a la mucosa intestinal. De este modo, contribuyen a mantener una flora normal y equilibrada. 
La flora intestinal ha evolucionado de la mano con la fisiología humana, y este proceso simbiótico ha dejado a la flora moderna llena de células de bacteria, la mayoría ubicadas en el colon: más o menos 100 trillones de células en total, que representan más de 1000 especies de bacterias (Eckburg et al., 2005) que aportan 600000 genes a cada ser humano (WGO, 2011). Esta actividad microbiológica interna, generalmente referida como flora intestinal, juega un papel importante en conservar la salud. Mediante la conformación y el mantenimiento normal de la inmunidad de la mucosa, la flora intestinal forma un "efecto barrera". La presencia de estas bacterias beneficiosas en el tracto intestinal ayuda a prevenir la colonización del intestino por patógenos y de este modo ayudan al cuerpo a defenderse de infecciones. La flora que se encuentra en el colon también está involucrada en la culminación del proceso digestivo, a través de la fermentación de sustancias como la fibra dietaria, los oligosacáridos, la fructosa y la lactosa que no son digeridas en el estómago o en el intestino delgado. La fermentación de carbohidratos produce ácidos grasos de cadena corta, especialmente butirato, que es la primera fuente de energía de las células de revestimiento del colon. Cuando los niveles de butirato se reducen o están ausentes, se pueden producir inflamaciones características de colitis ulcerosas. Finalmente, se ha demostrado que la flora intestinal también contribuye con la síntesis de vitamina $\mathrm{K}$ y aminoácidos y en la metabolización de ácidos biliares, otros esteroles y xenobióticos (Bäckhed, Ley, Sonemburg, Peterson y Gordon, 2005).

En cuanto a las especies y cepas, la diversidad microbiana entre los individuos es bastante notoria: cada individuo alberga su propio patrón distintivo de composición bacteriana, determinado en parte por el genotipo del huésped y por la colonización inicial al momento del nacimiento, por medio de la transmisión vertical (WGO, 2011).

La flora intestinal se encuentra en un estado constante de flujo, y el balance entre microbios o ecosistema en equilibrio puede ser alterado por la dieta, el alcohol, los alimentos contaminados, los antibióticos, el estrés y el envejecimiento, al igual que por desórdenes digestivos y enfermedades (Collins y Gibson, 1999). El desequilibrio (aumento de bacterias patógenas o disminución de bacterias beneficiosas) de la composición de la flora intestinal (disbiosis), puede disminuir el efecto barrera y contribuir a la aparición de dolencias, que incluyen malestar intestinal, estreñimiento, gases, dispepsia, alergias, etc.; que habrán de conducir al desarrollo de consecuencias más serias, como colitis ul- 
cerosas, síndrome del intestino, obesidad, diabetes tipos I y II, y enfermedad celiaca (Guarner y Malagelada, 2003).

La infección por Clostridium difficile o C. difficile en el colon es producida por una bacteria. Cuando la bacteria $C$ difficile crece rápidamente puede perturbar el equilibrio del colon y producir una inflamación en el revestimiento de este, lo cual conduce a una infección. Los antibióticos matan tanto las bacterias malignas como las benignas, lo cual podría alterar el balance normal de bacterias en el colon. El riesgo de adquirir una infección por $C$. difficile aumenta cuanto más largo sea el tiempo que se tome un antibiótico. El riesgo también aumenta si se toma más de un tipo de antibiótico. Un número pequeño pero creciente de médicos están usando los llamados trasplantes fecales para tratar el C. difficile. Pero los trasplantes fecales significan un reto para la agencia estadounidense Administración de Alimentos y Drogas (FDA, por sus siglas en inglés), que ha resuelto regular el tratamiento como si se tratase de una droga experimental.

La concentración de probióticos en alimentos se expresa en unidades formadoras de colonias (ufc) por gramo de porción, que es una indicación del número de microorganismos vivos presentes. Al día de hoy, no hay un nivel reconocido de unidades formadoras de colonias de bacterias probióticas en alimentos que garanticen actividad biológica (Ried, Anukam y Koyama, 2008). Sin embargo, el nivel promedio comúnmente reportado requerido para lograr efectos beneficiosos en alimentos que contienen probióticos es $>100$ millones $\left(10^{8}\right)$ de células viables/día (CFIA, 2009; Donnet-Hughes, Rochat, Serra, Aeschlimann y Schiffrin, 1999; Douglas y Sanders, 2008).

\section{PROBIÓTICOS EN PANIFICACIÓN Y PRODUCTOS HORNEADOS}

Una variedad amplia de cepas probióticas se añaden a una serie de alimentos. Los probióticos se encuentran a menudo en productos lácteos, pero cada vez más se están incorporando en otros alimentos, como jugos, barras de granola, chocolates, cereales, etc. La mayoría de microrganismos probióticos son bacterias productoras de ácido láctico, que usualmente son parte de una flora intestinal saludable. Las cepas Lactobaillus y Bifidobacterium son adicionadas comúnmente a los alimentos y suplementos. Las cepas Enterococcus spp., Bacillus spp., Escherichia coli y Saccharomyces bolulardii (levadura no patogénica) 
se venden comúnmente como suplementos, pero también pueden añadirse a los alimentos.

La viabilidad de probióticos en los alimentos depende de varias condiciones encontradas durante el procesamiento y almacenaje. La pérdida de probióticos durante procesos térmicos depende de la habilidad de la cepa de resistir el calor (Champagne, 2009). La mayoría de bacterias probióticas son sensibles al calor, de manera que su supervivencia durante los procesos térmicos es un obstáculo mayor. El calor involucrado en el proceso de horneado puede generar pérdidas significativas en viabilidad durante el proceso productivo y el almacenamiento de pan.

B. subtilis es una espora formadora de bacteria que tiene la capacidad de esporular cuando es expuesta a condiciones ambientales severas (Nicholson, Munakata, Horneck, Melosh y Setlow, 2000). Esta propiedad le confiere una ventaja mayor al utilizar B. subtilis como probiótico en el procesamiento de alimentos que utilizan procesos con temperaturas elevadas como el horneado. Cuando se encuentra en su forma esporulada, $B$. subtilis puede sobrevivir a choques térmicos, $\mathrm{pH}$ bajo, elevada compresión, elevada acidez, elevada actividad de agua, elevado contenido de azúcar y rayos UV (Setlow, 2006). Por ende, puede ser incorporado en cualquier etapa en el proceso de producción del pan, de galletas o de otro producto horneado.

\section{REGULACIONES EN ESTADOS UNIDOS}

En Estados Unidos, tanto la B. subtilis como la L. rhammosus tienen la categoría de productos GRAS $^{2}$ y son elegibles para poder declarar propiedades saludables. Sin embargo, la FDA no ha aprobado ninguna declaración de propiedades saludables para probióticos, porque aún no se ha establecido un valor diario recomendado. Las propiedades declaradas están referidas a beneficios estructurales/funcionales que no requieren aprobación de la FDA.

Los beneficios estructurales/funcionales se refieren al rol de un nutriente o ingrediente dietario, que afecta la estructura normal o función en los humanos.

2 Generalmente reconocidos como seguros. 


\section{EN EL PERÚ}

Los probióticos son productos relativamente nuevos, cuyo consumo va en aumento, principalmente en los productos lácteos, pero aún no cuenta con una regulación establecida para el rotulado, por lo cual no es necesario informar en las etiquetas ni el número ni el tipo de cepas probióticas que contienen. Sin embargo, en el mercado podemos apreciar que en los productos lácteos se rotulan los cultivos vivos de las cepas bacterianas, como Bifidobacterium Lactobacillus paracasei, Lactobacillus acidophilus y Lactobacillus rhamnosus.

El consumidor está apreciando la funcionalidad de los probióticos y los prebióticos. Ello se ve reforzado no solo por el aumento de alimentos que contienen ingredientes probióticos o prebióticos, sino por el aumento del número de productos que resaltan sus beneficios en la parte frontal de los envases.

\section{CONCLUSIONES}

La salud y el bienestar son cada vez más el centro de atención de los consumidores, quienes están más conscientes de la relación que existe entre dieta, ejercicio físico y salud. Los probióticos constituyen uno de los subgrupos más destacados entre los alimentos funcionales. Existe una gran oportunidad de mercado para los alimentos que contengan probióticos, que resultan importantes para el buen funcionamiento del sistema digestivo. Actualmente, los probióticos son utilizados en su mayoría en productos lácteos y alimentos basados en líquidos. Los productos lácteos constituyen un excelente vehículo para los probióticos, ya que los protegen de los elevados niveles de ácido que tiene nuestro estómago y de la concentración de bilis del intestino, que pueden dañar o eliminar a muchos de los probióticos que ingiramos. Es decir, consumir probióticos en lácteos aumenta la posibilidad de que las bacterias beneficiosas sobrevivan a su paso por el intestino.

Para el caso de productos horneados hay que trabajar con cepas que sean resistentes a la temperatura, lo cual también abre oportunidades de investigación para el desarrollo de este tipo de cepas.

Otra oportunidad interesante son los alimentos basados en cereales, como hojuelas y barras suplementados con bacterias probióticas. Sin embargo, la estabilidad de la cepa probiótica durante el almace- 
namiento de estos productos podría ser un problema. Se requerirán técnicas especiales para mejorar la estabilidad y asegurar que la cepa probiótica llegue viva al intestino de los consumidores, y en la concentración suficiente para causar un efecto favorable en la salud.

\section{REFERENCIAS}

Bäckhed, F., Ley, R. E., Sonnenburg, J. L., Peterson, D. A., y Gordon, J. J. (2005). Host-bacterial mutualism in the human intestine. Science, 37(5717), 1915-1920.

Bruhn, C. M., Bruhn, J. C., Cotter, A., Garret, C., Klenk, M., Powel, C., Stanford, G., Steinbring, Y., y West, E. (2002). Consumer attitudes toward use of probiotic cultures. Journal of Food Science, 67(5), 1969-1972.

Cáceres, P., y Gotteland, M. (2010). Alimentos probióticos en Chile: ¿qué cepas y qué propiedades saludables? Revista Chilena de Nutrición, 37(1), 97-109.

CFIA - Canadian Food Inspection Agency. (2009). Health claims: probiotic claim. Recuperado de http://www.inspection.gc.ca/ english/fssa/labeti/guide/ch8ae.shtml

Champagne, C. P. (2009). Some technological challenges in the addition of probiotic bacteria to food. Prebiotics and Probiotics Science and Technology, 761-864.

Collins, M. D., y Gibson, G. R. (1999). Probiotics, prebiotics, and symbiotic: Approaches for modulating the microbial ecology of the gut. American Society for Clinical Nutrition, 69(5), 1052- 1057.

Donnet-Hughes, A., Rochat, F., Serrant, P., Aeschlimann, J. M., y Schiffrin, E. J. (1999). Modulation of nonspecific mechanism of defense by lactic acid bacteria: Effective dose. Journal of Dairy Science, 82(5), 863-869.

Douglas, L. C., y Sanders, M. E. (2008). Probiotics and prebiotics in dietetic practice. Journal of the American Dietetic Association, 108(3), 510-521.

Eckburg, P. B., Bik., E. M., Berstein, C. N., Purdom, E., Dethlefsen, L., Sragent, M., Gill, S. R., Nelson, K. E., y Relman, D. A. (2005). 
Diversity of the human intestinal microbial flora. Science, 308(5728), 1635-1638.

FAO. (2006). Probióticos. Recuperado de http://www.fao.org/food/foodsafety-quality/a-z-index/probiotics/es/

FAO/WHO. (2001). Health and nutritional properties of probiotics in food including powder milk with live acid bacteria. Recuperado de http://www.who.int/foodsafety/publications/fs_management/ en/probiotics.pdf

FAO/WHO. (2002). Guidelines for the Evaluation of Probiotics in Food. Recuperado de http://htpp.fao.org/es/esn/food/wgreport2.pdf

Fuller, R. (1989). Probiotics in man and animals. Journal of Applied Bacteriology, 66(5), 365-378.

Guarner, F., y Malagelada, J. R. (2003). Gut flora in health and disease. Lancet, 361(9356), 512-519.

Hasler, C., Bloch, A., Thomson, C., Enrione, E., y Manning, C. (2004). Position of the American Dietetic Association: Functional foods. Journal of the American Dietetic Association, 104(5), 814-826.

Heller, L. (2009). Danisco breaks down probiotics market. Recuperado de http://www.nutraingredients-usa.com/Suppliers2/Daniscobreaks-down-probiotics-market

Lilly, D. M., y Stillwell, R. H. (1965). Probiotics: growth-promoting factors produced by microorganisms. Science, 147(3659), 747-748.

Metchnikoff, E. (1908). The prolongation of life. Optimistic studies. Londres: P. Chalmers Mitchell.

Nicholson, W. L., Munakata, N., Horneck, G., Melosh, H. J., y Setlow, P. (2000). Resistance of Bacillus endospores to extreme terrestrial and extraterrestrial environments. Microbiology and Molecular Biology Reviews, 64(3), 548-572.

Ohr, L. (2006). Beyond gut health. Food Technol, 60, 63-70.

Olagnero, G., Abad, A., Bendersky, S., Genovois, C., Granzella, L., y Montonati, M. (2007). Alimentos funcionales: fibra, prebióticos, probióticos y simbióticos. DIAETA (B. Aires), 25(121), 21-33.

O’Neill, J. (2007). Prebiotics: health and nutrition benefits in functional foods. Cereal Foods World, 52(1), 8-11. 
O'Neill, J. (2011). Health trends in snack and breakfast foods: how prebiotics play a starring role. Cereal Foods World 56(6), 232-234.

Parker, R. B. (1974). Probiotics, the other half of the antibiotics story. Animal Nutrition and Health, 29, 4-8.

Przemyslaw, J. K., y Piotr, T. (2003). Probiotics and prebiotics. Cereal Chemistry, 80(2), 113-117.

Ried, G., Anukam, K., y Koyama, T. (2208). Probiotic products in Canada with clinical evidence: what can gastroenterologists recommend? Canadian Journal of Gastroenterology, 22(2), 169-175.

Saarela, M., Mogense, G., Fondén, R., Matto, J., y Mattila-Sandholm, T. (2000). Probiotic bacteria: safety, functional and technology properties. Journal of Biotechnology, 84(3), 483-485.

Setlow, P. (2006). Spores spores of bacillus subtilis: their resistance to killing by radiation, heat and chemicals. Journal of Applied Microbiology 101(3), 514-525.

Van Nood, E., Vrieze, A., Nieuwdorp, M., Fuentes, S., Zoetendal, E., De Vos, E., Visser, C., Kuijper, E., Bartelsman, J., Tijssen, J., Speelman, P., Dijkgraaf, M., y Keller, J. (2013). Duodenal infusion of donor feces for recurrent clostridium difficile. New England Journal of Medicine, 368(5), 407-415.

WGO-World Gastroenterology Organization. (2011). Probióticos y prebióticos. Recuperado de http://www.worldgastroenterology. org/assets/export/userfiles/2012\%20Probiotics_NEW\%20 FINAL_sp.pdf 
